\title{
Comparison of Cost and Benefits between Wind Power Generation and Coal-Fired Power Generation
}

\author{
Fanghui Tan \\ School of Economics and Management, North China Electric Power University, Beijing, China \\ tfhclara@163.com
}

Keywords: Wind curtailment; Cost and benefits; Environmental cost; Ancillary service

\begin{abstract}
With the expansion of wind power installed capacity, the phenomenon of wind curtailment is getting more and more serious. Based on the cost and benefit of wind power plants and coal-fired plants in Jiuquan, Gansu province, this paper focuses on the conflicts between different generation ways. Firstly, by using the dynamic cost analysis method and the marginal cost analysis, the average cost of each additional unit capacity of coal-fired power plants can be calculated. Secondly, according to the theory of product life cycle and the pollution loss method, the monetary value of the environmental impact is calculated in three stages. And the external cost of each unit can be calculated. Thirdly, the cost of wind power plants can be divided into wind power enterprise investment cost and ancillary service cost. By curve simulation, we can get the cost of wind power investment. According to the analysis of load duration curve and on-grid price, we get the total cost of ancillary services. Combined with the tax system and input-output analysis, financial revenue and industry driving benefits of the two generation ways can be calculated. Finally, we find that the total profit of wind power generation is higher and propose policies to promote the development of wind power in China.
\end{abstract}

\section{Introduction}

In the context of global initiatives to promote energy conservation and improve the atmospheric environment, China is stepping up efforts to change the energy structure. Replacing the use of coal with cleaner energy is a key point. In 2009, China promulgated the Renewable Energy Law, in the form of legislation to ensure the priority use of clean energy.

According to the assessment of meteorological department, the total wind energy resources in Jiuquan, Gansu Province can be up to 150 million kilowatts. Compared with coastal areas, northeast China and Inner Mongolia and Xinjiang, the wind energy resources in Jiuquan have unique advantages: No destructive wind speed is extremely beneficial to the utilization of wind power and suitable for the construction of large-scale grid-connected wind farms.

On May 4, 2009, Gansu Provincial Development and Reform Commission revealed that the planning report adopted a formal proposal to build a 10-million kilowatt-class wind power base in Jiuquan. If this could come into reality, it could become the largest wind power base in China and help relieve the power shortage in the north and east of China. Up to 2015, the installed capacity of wind power has ranked first around the world.

However, it is estimated that the average wind abandoned rate was close to $15 \%$ in 2015 , especially in some areas, the rate was even 30\%. [1] In Gansu Province where the wind energy resource is abundant, the average number of wing power utilization hours is less than 1200, while this number could be up to 2100-2300 without wind power limitation.

In fact, there exists some conflicts for this problem among Gansu, State Grid Corporation of China (SGCC) and other areas in China. Gansu province tried to develop its wind power base; the SGCC hoped to promote the development of interconnected power grid; generation companies in central China preferred the relatively low-price coal and promote the coal-fired generation to improve economic development. Therefore, it has been a tough problem to corporate the interests of all groups and realize the "Innovation, Green, Coordination, Openness and Sharing" proposed by president Xi. 
In this paper, we employ models to compare the cost and benefits of coal-fired generation and wind power generation. By establishing measurement indexes and compare the results, we find that the total profit of wind power generation is higher. Note that this paper is based on the short-term operational cost and benefits accounting after the investment, so the generating cost refers to the operational cost. The process can depicted as Figure 1.

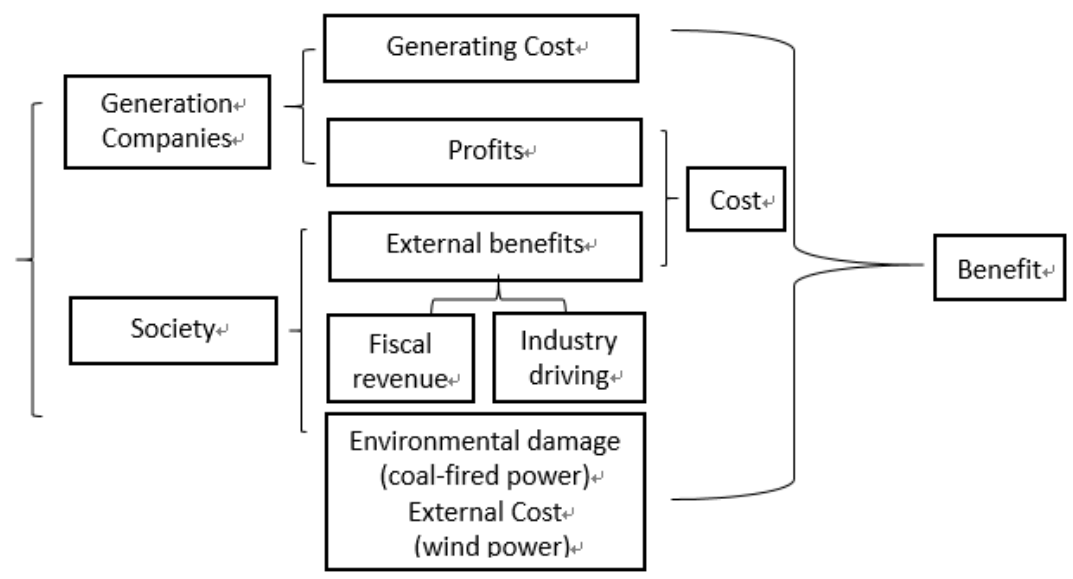

Figure 1. Accounting process of cost and benefit for social welfare

Where, Profits $=$ on-grid price - the generating cost of $1 \mathrm{kwh}$. Unit: RMB yuan $/ \mathrm{kwh}$ The measurement index of coal-fired power and wind power can be expressed respectively.

$$
\begin{aligned}
K_{c} & =\frac{\text { Profits }+ \text { External benefits }}{\text { Generationg cost }+ \text { Environmental damage }} \\
K_{w} & =\frac{\text { Profits }+ \text { External benefits }}{\text { Generationg cost }+ \text { Environmental damage }}
\end{aligned}
$$

\section{Cost Accounting and Comparison of Wind and Coal-fired Power Generation}

Operational Cost of a Coal-fired Power Generation Company. Based on the principle of marginal cost, we can calculate the required cost of each additional unit of electricity. The cost can be classified into two categories, including variable cost and fixed cost.

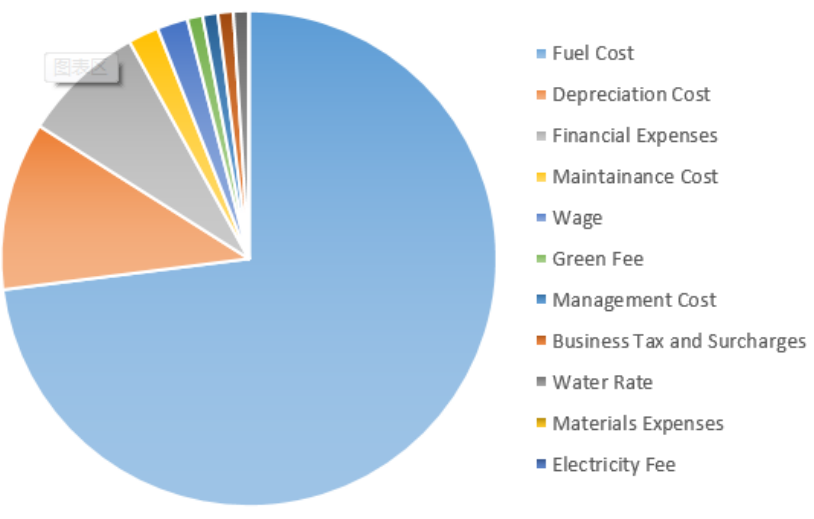

Figure 2. The operational cost of a coal-fired power plant

For those the variable cost which has linear association with power generation capacity, including fuel costs and water rate, we should take the actual consumption of the unit as a basis for calculation. And we also should consider the fuel cost and water rate during the startup and stopping period, which are not out of proportion with generating capacity.

$$
F_{v}=F_{R M}+F_{R Y}+F_{W}+F_{Q T}
$$

Where $F_{v}$ represents the real-time variable cost; $F_{R M}$ represents coal-fired cost; $F_{R Y}$ represents 
oil-fired cost; $F_{w}$ represents water rate; $F_{Q T}$ represents start-up and shut-down cost.

Table 1 The result of fixed cost
\begin{tabular}{|c|c|}
\hline Project & Unit: RMB yuan \\
\hline Material Cost & 644.68 \\
\hline Depreciation Cost & 18587.11 \\
\hline Wage & 4230.71 \\
\hline Maintenance Cost & 2849.92 \\
\hline Others & 4233.28 \\
\hline Total & 30545.7 \\
\hline
\end{tabular}

Therefore, at last the total operational cost of a coal-fired power plant is about RMB $0.125 y u a n /$ Kwh.

Operational Cost of a Wind Power Generation Company. The wind power investment costs mainly include two categories, the one is the wind power project construction $\operatorname{cost} C_{1}$, which is one of the most important factors affecting the cost of wind power enterprises. [2] The cost of wind turbines, installation and commissioning expenses, wind farm infrastructure cost and network connection cost are included in $C_{1}$. Another is the management and maintenance cost of wind power equipment $C_{2}$. In this paper, we are based on the existing wind power plant, so we will not take the cost of wind turbines and wind farm infrastructure into consideration. As a result, in this paper $C_{1}$ mainly includes network connection cost and other daily operational cost.

$$
C_{1}=E_{n}+b
$$

Where $E_{n}$ represents the connection network cost.

The investment cost of per unit capacity can be expressed:

$$
c_{i}=\frac{C_{1}+C_{2}}{n Q_{V}}=\frac{C}{8760 U_{r} P}+\frac{C}{1876 \sigma_{r}}
$$

Where $Q_{w}$ represents the annual energy output of wind turbine generators, which can be estimated according to the capacity factor $U_{e}$ of a wind farm. $P_{a}$ represents Output power; $P_{r}$ represents rated power. $Q_{w}=8760 P_{a}=8760 U_{e} P_{r}$

After learning curve simulation [5] and linear analysis from 1997 to 2012, the cost of wind power in 2015 is about RMB 0.20 yuan /Kwh.

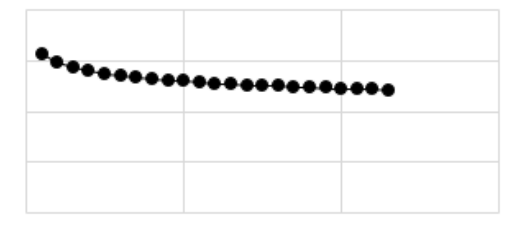

Figure 2. The learning curve of wind power per unit

According to the grid-integration price system, the total ancillary service cost includes the on-grid price part and the auxiliary service fund part. [3]

According to relevant institutions, in 2020 the electricity consumption in China will be 8 trillion Kwh. In addition, the installed capacity of hydropower in 2015 is about 246 million KW, expected to be about 350 million $\mathrm{KW}$ in 2020 , while the installed capacity of nuclear power is about 80 million KW. As for other renewable energy generation, such as biomass power generation, solar photovoltaic power generation, whose scale are relatively small and can be negligible in this paper. The annual utilization hours of power generation technology are set as 2000 for wind power, 3500 for hydropower, 7500 for nuclear power. Data shows that the peak-load service in China mainly relied on coal-fired units, so we take the $600 \mathrm{MW}$ supercritical coal-fired units as the representatives of coal-fired units to do the service. Also, set the annual utilization hour of coal-fired on-grid price as 5300. Therefore, combined with the investment cost and Ancillary service cost, the total cost of wind power generation is about 0.2 yuan/kwh from wind farm users. By 2020, 
this index is expected to be 0.1862 yuan $/ \mathrm{kwh}$.

External Cost of Coal-Fired Power Generation. In addition to the operational costs, in fact the cost of coal-fired power generation is far more than that because of the environmental damage it caused. Economists refer to this effect of non-market influence as externality. In the calculation of external costs, we should take the coal life cycle as a calculation period. According to the product life cycle theory, it can be divided into three stages, mining, transportation and utilization.

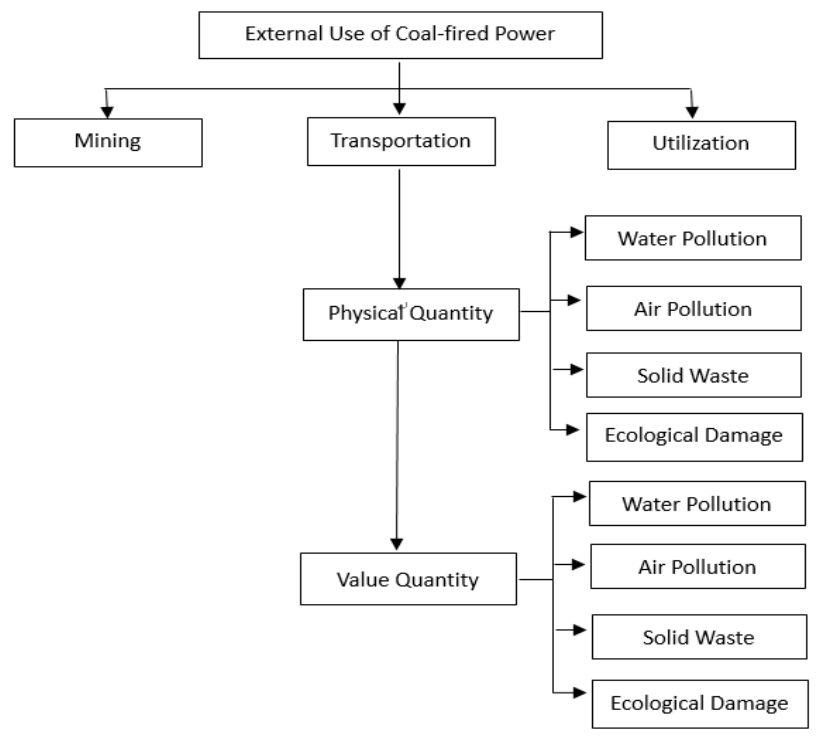

Figure 3. The flow chart of external cost accounting

According to relevant statistics and pollution loss method, the external cost of coal-fired power generation is $0.127 \mathrm{yuan} / \mathrm{kwh}$. This monetary value has not around the concern of governments, but the environmental effects have been increasingly important.

External Cost of Wind Power Generation. If the quota of coal-fired power could be distributed to wind power, the coal-fired generation company could get the compensation for $0.5 \mathrm{yuan} / \mathrm{kwh}$, which could be taken as the external cost of wind power generation. [4]

\section{External Profits of Wind and Coal-fired Power Generation}

Fiscal Revenue. In Gansu province, the original investment for a wind farm is $9100 \mathrm{yuan} / \mathrm{kwh}$, where private capital accounts for $80 \%$ and national commercial loan accounts for $20 \%$, with a rate of $7.05 \%$. The depreciation period is 20 years and the residential value of investment is $5 \%$. The utilization hour of wind power generation is 2000 . Take a $200 \mathrm{MW}$ wind power farm as an example and the on-grid price for wind power is 0.58yuan $/ \mathrm{kwh}$ in Gansu [6], so the total fiscal revenue of a wind power generation company could be 564.87 billion. The fiscal revenue per unit is RMB 7.081yuan/kwh.

Similarly, take the 200MW coal-fired generation company as an example. The original investment is 4212 yuan $/ \mathrm{kwh}$. The lifetime of a unit is 30 years; the depreciation period is 20 years and the residential value could be ignored. According to the statistics in 2014, the coal consumption is $343 \mathrm{~g} / \mathrm{kwh}$. Assume the coal price is 380 yuan $/ \mathrm{t}$ and the on-grid price is $0.325 \mathrm{yuan} / \mathrm{kwh}$ [7]. Finally we can calculate that the total fiscal revenue is 895.51 billion yuan during the 30 years. Since the utilization hour of coal-fires generation is 5500, the fiscal revenue per unit is RMB 2.714 yuan/kwh.

Industry Driving Effects. According to industrial interrelated theory, there exists an industrial chain based on the forward and backward connection. For example, the relevant industries of coal electricity are in Figure 4. 


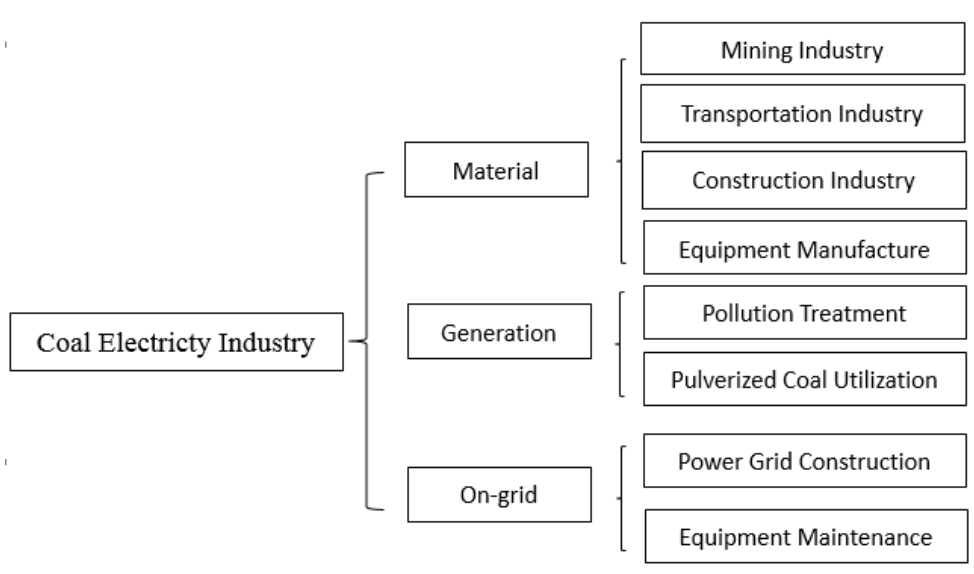

Figure 4. The relevant industries of Coal-fired Power

\section{Results and Conclusion}

After numerical analysis and data substitution, the final measurement index can be calculated.

$$
K_{w}=12.631, K_{c}=9.827, K_{w}>K_{c}
$$

Therefore, the total profits of wind power generation in Gansu Province is higher.

\section{Policy Suggestions}

Now the problem is neither electricity shortage, nor transmission problems, but the users do not want to use the wind power energy. If the wind power generated in Gansu transported to Hubei and Hunan province for use, the tax revenue and benefits still belong to Gansu, which will cause damage to the economic development in Hubei and Hunan province. Furthermore, the poor stability of wind power also affected the willingness of Hunan and Hubei to use it. We can propose some suggestions:

(1) Establish a unified emissions trading market aiming to control the total carbon emission. [8, 9]

(2) Implement the quota of non-water renewable energy generation and establish the balance account. [10]

(3) Improve the wind power trading system to balance the interests of all parties. Based on the balance of interests and risks, promote the development of wind power generation.

\section{Reference}

[1] National Energy Administration: The development of wind power industry in 2015 (In Chinese)

[2] Q.L. Cheng: Research on Cost Analysis of Wind Power Generation Enterprises based on Value Chain (MS., North China Electric Power University, China 2014) (In Chinese)

[3] Y. He, J.F. Hu, Z.T. Yan and J.C. Shang: Compensation Mechanism for Ancillary Service Cost of Grid-Integration of Large-Scale Wind Farms, Power System Technology, Vol.37 (2013) No.12, p.3552-3557. (In Chinese)

[4] X.L., Zhao, S.F., Zhang, Y.S. Zou and J. Yao: To what extent does wind power deployment affect vested interests? A case study of the Northeast China Grid, Energy Policy, Vol. 63 (2013) No.4, p.814-822.

[5] Y.C. Zhu, L. Lin, J.J Xu and D.M. Zhao: Analysis of wind power cost based on learning curve, Power Demand Side Management, Vol. 14 (2012) No.4, p.11-13

[6] Information on http://gansu.gansudaily.com.cn/system/2015/04/22/015490554.shtml

[7] Information on http://gs.people.com.cn/n2/2016/0707/c184701-28627089.html

[8] X.C. Liu and Z.T. Wang: The comparison of Policies of Carbon Emission Reduction and Chinese Optimized Choice, Journal of Shanghai University of Finance and Economics, Vol. 11 (2009) No.4, p.73-80. (In Chinese) 
[9] Information on http://www.tanpaifang.com/tanjiaoyi/2017/0105/58168.html

[10] European Environment Agency: Environmental taxes: implementation and environmental effectiveness, Office for Official Publications of the European Communities, 1996 